\title{
Research on the Characteristics of Environmental Air Pollution and Its Countermeasures in Tianjin
}

\author{
Qingmin Yuan, Jiebing Li ${ }^{*}$ \\ School of Management, Tianjin University of Technology, Tianjin, China
}

\begin{abstract}
With the rapid economic and social development, environmental protection is facing many challenges, especially air pollution. It is an urgent task to study and recognize the current situation of air pollution and its causes, and to take corresponding measures. In this paper, by analyzing the status and changing trend of air environmental quality of Tianjin, the research of main pollutant and the characteristics of pollutants in the air of frequency, pollution characteristics, pollution change law and stress time, on the basis of put forward the countermeasure and the suggestion of collaborative control more pollutants, to provide accurate ShiCe, scientific control science and technology support, provide scientific support to win the battle blue sky.
\end{abstract}

Keywords: Air pollution, pollution characteristics, Prevention and control countermeasures.

\section{Introduction}

Along with urbanization, industrialization, the rapid development of regional economic integration process, a large number of air pollutants emissions lead to increasing atmospheric environmental pollution in our country, presents the structural and complex characteristics of heavy pollution weather frequent, covering the area of large, long duration, and the extent of influence has seriously affected the people's production and living, health and restricted the economic and social sustainable development, prevention and control of atmospheric pollution situation is very grim[1].

Tianjin attaches great importance to the prevention and control of air pollution, has taken a series of strong measures to improve regional air quality, and has fulfilled the phased tasks and annual targets stipulated in the Action Plan for The Prevention and Control of Air Pollution of the State Council. However, the urban air quality is still poor, and the pollutant concentration index is still high. In order to promote the prevention and control of air pollution in Tianjin and further improve the regional air quality, this paper investigated, sorted out, summarized and analyzed the environmental air quality in Tianjin urban area in recent years, studied its pollution characteristics, pollution frequency and change rule, and put forward corresponding countermeasures and Suggestions.

*Corresponding author: soluckybing@stud.tjut.edu.cn 


\section{Environmental air quality in Tianjin}

Tianjin is located between longitude $116^{\circ} 43^{\prime}$ and $118^{\circ} 04^{\prime}$ east and latitude $38^{\circ} 34^{\prime}$ to $40^{\circ} 15^{\prime}$ north. The city center is located at $117^{\circ} 10^{\prime}$ e and $39^{\circ} 10^{\prime}$ n. It is located in the north Of North China Plain, with Bohai Sea in the east and Yanshan Mountain in the north. Tianjin is located in the lower reaches of the Haihe River, spanning both sides of the Haihe River. It is the traffic throat and ocean-going shipping port from Beijing to the northeast and east China regions. It is known as "the key crossing of the river and sea" and "the gateway of Gigi Auxiliary". It is $189 \mathrm{~km}$ long in the north and $117 \mathrm{~km}$ wide in the west and east.

The terrain is mainly plain and depressions, with low hills and hills in the north, and the altitude gradually drops from north to south. The highest in the north, 1052 meters above sea level; Lowest in the southeast, $3.5 \mathrm{~m}$ above sea level. The general contour of landform is high in the northwest and low in the southeast. Tianjin has three kinds of landforms: mountain, hill and plain, and plain accounts for about $93 \%$.In addition to the north and yanshan south border is mostly mountainous, the rest are alluvial plain, Jizhou district northern mountainous areas for the altitude of kilometers below the low hills. Close to the mountain area is an inclined plain composed of alluvial fan, fan - like distribution. To the south is the alluvial plain and to the southeast is the coastal plain[2].

Tianjin is located in the north temperate zone on the east coast of mid-latitude Eurasia continent, mainly dominated by monsoon circulation. It is the region where the East Asian monsoon prevails, and it has a warm temperate semi-humid monsoon climate. Adjacent to Bohai Bay, the Marine climate has an obvious influence on Tianjin[2].The main climatic features are four distinct seasons, windy spring, drought and little rain; Hot summer, concentrated rain; Autumn cool, warm and cold moderate; Winter is cold and dry with little snow.

\subsection{The overall trend is positive}

According to the data of Tianjin automatic monitoring network of ambient air quality, the ambient air quality in Tianjin is generally stable and getting better in recent years. The annual average concentration of major pollutants $\mathrm{SO}_{2}, \mathrm{NO}_{2}, \mathrm{PM} 10$ and PM2.5 is on the whole declining, the number of days with good air quality is increasing year by year, and the rate of good and good is increasing year by year. The average annual PM10 concentration in 2019 is $37 \%$ lower than that in 2015 , and the proportion of days with good air quality is $6.2 \%$ higher than that in 2017, as shown in Table 1 and Table 2.

Table 1. Concentration of major pollutants in Tianjin

\begin{tabular}{|c|c|c|c|c|c|c|}
\hline \multirow{2}{*}{ Year } & \multicolumn{7}{|c|}{ Annual Mean Value of Major Pollutants $\left(\mathrm{ug} / \mathrm{m}^{3}, \mathrm{CO} \mathrm{mg} / \mathrm{m}^{3}\right)$} \\
\cline { 2 - 8 } & $\mathrm{PM} 2.5$ & $\mathrm{PM} 10$ & $\mathrm{SO}_{2}$ & $\mathrm{CO}$ & $\mathrm{NO}_{2}$ & $\mathrm{O}_{3}$ \\
\hline 2015 & 69 & 120 & 29 & 1.4 & 41 & 77 \\
\hline 2016 & 69 & 103 & 21 & 2.7 & 48 & 157 \\
\hline 2017 & 62 & 94 & 16 & 2.8 & 50 & 192 \\
\hline 2018 & 52 & 82 & 11 & 1.9 & 47 & 201 \\
\hline 2019 & 51 & 76 & 11 & 1.8 & 42 & 200 \\
\hline national standard & 35 & 70 & 60 & 4 & 40 & 160 \\
\hline Note: Gb3095-2012 ambient air quality standard shall be implemented from 2015 to 2019. \\
(the same below) \\
\hline
\end{tabular}


Table 2. Statistical table of days with good air quality in Tianjin

\begin{tabular}{|c|c|c|c|}
\hline Year & Good days & Effective number of days & Ratio (\%) \\
\hline 2017 & 209 & 365 & 57.3 \\
\hline 2018 & 207 & 365 & 56.7 \\
\hline 2019 & 222 & 365 & 60.8 \\
\hline
\end{tabular}

\subsection{Compliance Analysis}

From 2015 to 2019, the annual average concentration of $\mathrm{SO}_{2}$ in Tianjin is 0.011-0.029 $\mathrm{mg} / \mathrm{m}^{3}$, and the annual average concentration of CO for 24 hours is $1.4-2.8 \mathrm{mg} / \mathrm{m}^{3}$, which meets the second-level standard of GB3095-2012 Environmental Air Quality Standard. However, the average annual concentration of PM10, PM2.5 and $\mathrm{NO}_{2}$ does not meet the secondary standard. Ozone $\left(\mathrm{O}_{3}\right)$ increased year by year, far exceeding the secondary standard.

\subsection{Pollution characteristics}

\subsubsection{Primary pollutant}

See Table 3 for the proportion of primary air pollutants in Tianjin. The data showed that the primary pollutants affecting the air quality in Tianjin were PM2.5, PM10, $\mathrm{NO}_{2}$ and $\mathrm{O}_{3}$. Among them, ozone accounts for the largest proportion, reaching more than $42 \%$, which is the most prominent, and the impact of ozone on the environment is increasingly prominent.

Table 3. Statistics on the primary pollutants of Air quality in Tianjin

\begin{tabular}{|c|c|c|c|c|c|c|c|c|}
\hline \multirow{2}{*}{ Year } & \multicolumn{2}{|c|}{ PM2.5 } & \multicolumn{2}{c|}{ PM10 } & \multicolumn{2}{c|}{$\mathrm{NO}_{2}$} & \multicolumn{2}{c|}{$\mathrm{O}_{3}$} \\
\cline { 2 - 9 } & $\begin{array}{c}\text { Number of } \\
\text { days }\end{array}$ & Ratio & $\begin{array}{c}\text { Number of } \\
\text { days }\end{array}$ & Ratio & $\begin{array}{c}\text { Number of } \\
\text { days }\end{array}$ & Ratio & $\begin{array}{c}\text { Number of } \\
\text { days }\end{array}$ & Ratio \\
\hline 2019 & 93 & $29.6 \%$ & 42 & $13.4 \%$ & 47 & $15 \%$ & 132 & $42 \%$ \\
\hline
\end{tabular}

\subsubsection{Pollution of the frequency}

From 2017 to 2019, the frequency of mild environmental air pollution in Tianjin was 296 times (days), accounting for $26.8 \%$ of the total days. Data show that in recent years, the city's air quality has improved significantly, with the number of days with mild pollution and heavy pollution decreasing year by year, and the number of days with heavy pollution decreasing by $39.1 \%$, see Table 4 for details.

Table 4. Statistics of environmental air pollution frequency in Tianjin in recent three years

\begin{tabular}{|c|c|c|c|c|}
\hline Year & $\begin{array}{c}\text { Mildly polluted } \\
\text { days }\end{array}$ & $\begin{array}{c}\text { Moderately polluted } \\
\text { days }\end{array}$ & $\begin{array}{c}\text { Heavy pollution } \\
\text { days }\end{array}$ & contamination rate(\%) \\
\hline 2017 & 99 & 34 & 23 & 42.7 \\
\hline 2018 & 109 & 39 & 10 & 43.3 \\
\hline 2019 & 86 & 42 & 14 & 38.9 \\
\hline
\end{tabular}

\subsubsection{Spatial and temporal distribution of pollution}

According to statistical analysis, the air pollution frequency in Tianjin mainly occurs in 
January-February and June-July, and the months with low pollution frequency are March and August. The high frequency of pollution in January-February is mainly influenced by factors such as low precipitation, more static and stable weather, poor diffusion conditions and sand and dust weather in the north. The primary pollutant from June to July is ozone (O3), as shown in Figure 1.

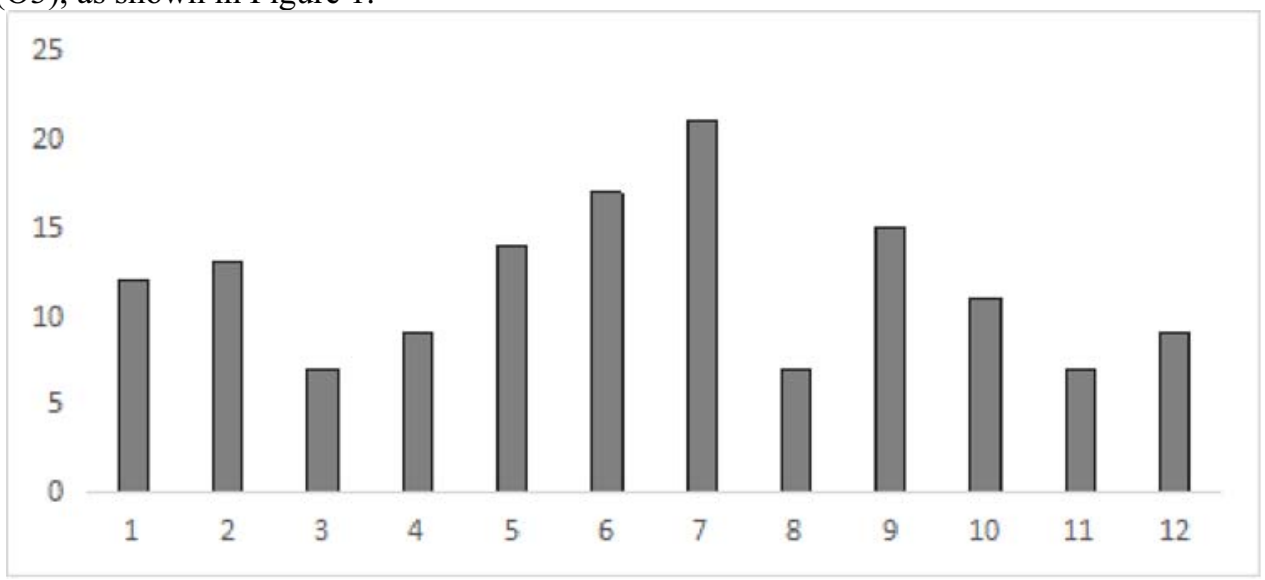

Figure 1. Spatial and temporal distribution of ambient air pollution in Tianjin in 2019

\section{Analysis of problems and causes}

\subsection{The quality is still poor}

Tianjin environmental air quality and national standard (GB3095-2012) of the second level (that is, the air quality is good), there is still a considerable distance, air pollution prevention and control is a long way to go. Since 2015, the best year for the average daily concentration of PM10 in Tianjin is 2019 (76 micrograms per cubic meter), but it still fails to meet the national level ii standard (70 micrograms per cubic meter). The best year for the annual mean concentration of PM2.5 is 2019, and the annual mean concentration is 51 micrograms per cubic meter, still higher than the national standard limit of 35 micrograms per cubic meter. The best year for the annual mean concentration of NO2 was 2019, and the annual mean was $42 \mathrm{MCG} / \mathrm{m}^{3}$, which was close to the national standard limit of 40 $\mathrm{MCG} / \mathrm{m}^{3}$.

\subsection{Ozone problem highlights}

From 2015 to 2019 , the annual average daily ozone concentration at the 90th percentile in Tianjin was on the rise, and from 2017 to 2019, the annual average daily ozone concentration at the 90th percentile in Tianjin exceeded the standard, which was 192, 201 and $200 \mathrm{MCG} / \mathrm{m} 3$, respectively. Data show that in recent years, the proportion of ozone as the primary pollutant in Tianjin has gradually increased, and it has far exceeded the proportion of fine particulate matter (PM2.5), ranking the highest in China. Especially from April every year, with the increase of temperature and rainfall, the decrease of particulate matter is obvious. Ozone, as the dominant pollutant in summer and autumn, gradually becomes prominent and becomes increasingly prominent, and becomes a prominent factor affecting the rate of reaching the standard on days with good air quality in cities[3]. 


\subsection{The reason analysis}

There are mainly the following five reasons: first, ideological attention is not enough. In recent years, the city has not paid enough attention to the prevention and control of air pollution, especially some specific indicators such as ozone, which have not been placed on the important agenda and regarded as the general arrangement of work, leading to the failure of the implementation of various governance measures. Second, the responsibility transmission is not enough. The prevention and control of air pollution involves many management bodies. Responsibility and pressure have not been truly transmitted to regions, departments and enterprises. The implementation of "one post and two responsibilities" for environmental protection is not enough. Third, the rectification is not enough. Dust control on construction sites and roads is not complete; Industrial pollution is still very serious, volatile organic compounds, "small scattered pollution" enterprises control ineffective; The storage yard of Yiyang Powder, such as coal pile, material pile, slag pile and sand pile, is not properly controlled; Straw and garbage incineration, cooking fume pollution, motor vehicle exhaust and other governance is not in place; Some temporary control measures have not been put in place as required. Fourth, precise measures are not enough. The investigation and research work is not solid, the basic work has not been carried out, the level of pollution is not clear, the prevention and control of pollution cannot be carried out detailed analysis, precise and effective, and the treatment effect is only half effective with less effort. Fifth, regional co-governance is not enough. There is no boundary for the prevention and control of air pollution, and the joint prevention and control between Tianjin city and surrounding cities and counties is not enough[5]. Imported pollution occurs from time to time, especially in winter and spring.

\section{Countermeasures and Suggestions}

\subsection{Raise awareness and fulfill responsibilities}

The report to the 19th National Congress of the COMMUNIST Party of China (CPC) pointed out that we should focus on solving prominent environmental problems, adhere to the principle of universal co-governance, prevent and control pollution at its source, and continue to take action to prevent and control air pollution, so as to win the battle to protect the blue sky. Party committees and governments at all levels should earnestly raise their political standpoints, put the prevention and control of air pollution on the important agenda, and take strong measures to make solid progress. It has made it clear that party committees and governments at all levels are the primary responsible persons for the prevention and control of air pollution in their respective regions, and that they take overall responsibility for the prevention and control of air pollution in person and study major issues in a timely manner. Departments conscientiously fulfill "pipe industry must tube pipe environmental protection, the development environmental protection departments of responsibility, establish industry environment supervision, supervision, the mechanism of task decomposition to post, the prevention and control of atmospheric pollution to the man's head, ensure that every link of responsibility someone stop, someone tube, trying to form a complete coverage of" grid ", should the good situation.

\subsection{Strengthen research and adopt precise measures}

Research work as soon as possible to carry out prevention and control of atmospheric pollution, atmospheric pollution source analysis and source list, find out the regional air 
pollution characteristics and local pollution situation, establish a list of emission source, fine air pollution prevention and control measures, targeted control prominent atmospheric pollution, strengthen scientific, precision of the atmospheric environment governance, atmospheric pollution emissions management "peak frequency reduction".

\subsection{Strengthen measures and speed up rectification}

Combining the results of source analysis and source list research, adhering to the problemoriented, goal-oriented and result-oriented approach, the task of air pollution prevention and control is implemented in specific projects, enterprises, regions, road sections and points, urging all local departments to strengthen measures and promptly rectify them, so as to maintain the high-pressure situation of air pollution prevention and control and ensure effective results. In the event of heavy pollution weather, we should enter a state of early warning as soon as possible and take active measures to deal with it.We will establish a joint regional air pollution prevention and control mechanism to improve regional air quality.

\subsection{Strengthen assessment and ensure strict accountability}

We will establish strict supervision and control mechanisms for the prevention and control of air pollution, strengthen target responsibility assessment, and increase accountability and accountability. For those units that fail to make effective rectification work, or make slow progress, or fail to make rectification on time, relevant units and personnel will be held accountable in accordance with the law and discipline, and we will adopt a reprisal mechanism to put pollution control into effect, achieving tangible results.

\subsection{Introduce talents and strengthen support}

Involving multidisciplinary expertise, for the control of air pollution on the city's environmental protection system the present situation of the serious lack of atmospheric science and technical personnel, active introduction of atmospheric science, meteorology and other aspects of high-quality professional and technical personnel, engaged in fog haze, pollution characteristics, trends, research, early warning forecast, etc, and to achieve more accurate analysis and early warning forecast, rapid response and response to heavy pollution weather provide strong technical support, training apparatus, and LingJunXing talents team.

\subsection{Strengthen publicity and extensive participation}

Increasing propaganda, advocate the concept of ecological civilization society, establish and improve the government guiding demonstration is given priority to, the community, schools, enterprises, social organizations, mass media participation of ecological civilization publicity and education network, the ecological and environmental protection, moderate consumption, green travel, the concept of low carbon life to each unit, family and individual, atmospheric pollutants emissions by sources of further cuts in social life, improve the huanggang environment air quality.

\section{References}

1. Hao, LUO, Yong, et al. Characteristics of Surface Solar Radiation under Different Air 
Pollution Conditions over Nanjing, China: Observation and Simulation[J]. Advances in Atmospheric ences, 2019, 36(10):1047-1059.

2. Shi H, Critto A, Torresan S, et al. The Temporal and Spatial Distribution Characteristics of Air Pollution Index and Meteorological Elements in Beijing, Tianjin, and Shijiazhuang, China[J]. Integrated Environmental Assessment \& Management, 2018, 14(06):710-721.

3. Bhandari S, Maruthi Sridhar B B, Wilson B L . Effect of Land Cover Changes on the Sediment and Water Quality Characteristics of Brays Bayou Watershed[J]. Water Air and Soil Pollution, 2017, 228(9):336.

4. Tang B Y, Xin J Y , Gao W K, et al. Characteristics of complex air pollution in typical cities of North China[J]. Atmospheric \& Oceanic ence Letters, 2018:1-8.

5. Mehmood K, Chang S, Yu S , et al. Spatial and temporal distributions of air pollutant emissions from open crop straw and biomass burnings in China from 2002 to 2016[J]. Environmental Chemistry Letters, 2018, 16(1):301-309.

6. Li X, Peng L, Yao X, et al. Long short-term memory neural network for air pollutant concentration predictions: Method development and evaluation[J]. Environmental Pollution, 2017, 231(pt.1):997-1004. 